\title{
Ultra-performance liquid chromatography-tandem mass spectrometric determination of ramipril in human plasma
}

\author{
Sherif A Abdel-Gawad ${ }^{1,2 *}$, Safar M Alqahtani ${ }^{1}$ \\ ${ }^{1}$ Pharmaceutical Chemistry Department, College of Pharmacy, Prince Sattam Bin-Abdul Aziz University, Al-Kharj, Kingdom of \\ Saudi Arabia, ${ }^{2}$ Analytical Chemistry Department, Faculty of Pharmacy, Cairo University, Cairo, Egypt \\ *For correspondence: Email: sagawad@yahoo.com
}

Sent for review: 11 September 2019

Revised accepted: 23 January 2020

\begin{abstract}
Purpose: To develop a sensitive and accurate ultra-performance liquid chromatography-tandem mass spectrometric (UPLC-MS) method for quantification of ramipril in human plasma.

Methods: Ramipril was extracted from biological fluid using equal volumes of $n$-hexane and propanol $(1: 1, v / v)$, and then chromatographed in a suitable C18 column with methanol: $0.1 \% \mathrm{HCOOH}(4: 1, v / v)$ as mobile phase. Atorvastatin was used as an internal standard for the chromatographic separation and quantification. The method was validated according to the United States Food and Drug Administration guidelines for standard indices.

Results: Ramipril was determined in the concentration range 0.05 and $1000 \mathrm{ng} / \mathrm{mL}$ the validation procedure exhibited a correlation coefficient of $0.9979+0.002(p=0.05)$. The studied drug was quantified with lower ceiling of $0.05 \mathrm{ng} / \mathrm{mL}$, and showed an accuracy of $105.00 \%$.

Conclusion: A sensitive UPLC-MS analytical method has been successfully developed for the quantification of ramipril in human plasma. This method can be applied efficiently for the quantification of ramipril in bioavailability and pharmacokinetic studies.
\end{abstract}

Keywords: Liquid chromatography-tandem mass, Ramipril, Stability, Biological fluids, Plasma

\begin{abstract}
This is an Open Access article that uses a fund-ing model which does not charge readers or their institutions for access and distributed under the terms of the Creative Commons Attribution License (http://creativecommons.org/licenses/by/4.0) and the Budapest Open Access Initiative (http://www.budapestopenaccessinitiative.org/read), which permit unrestricted use, distribution, and reproduction in any medium, provided the original work is properly credited.

Tropical Journal of Pharmaceutical Research is indexed by Science Citation Index (SciSearch), Scopus, International Pharmaceutical Abstract, Chemical Abstracts, Embase, Index Copernicus, EBSCO, African Index Medicus, JournalSeek, Journal Citation Reports/Science Edition, Directory of Open Access Journals (DOAJ), African Journal Online, Bioline International, Open-J-Gate and Pharmacy Abstracts
\end{abstract}

\section{INTRODUCTION}

Hypertension is a serious condition associated with an elevation in blood pressure. It is known as the silent killer because in some cases, it manifests no clear symptoms. Uncontrolled persistent high blood pressure may lead to serious diseases like heart failure, stroke, atrial fibrillation and kidney malfunction [1]. Ramipril (RAM) can be considered as a prodrug, since it needs bio-transformation into the active form ramiprilate. Ramipril (RAM) is an antihyper- tensive drug which acts by inhibiting angiotensin converting enzyme (ACE). Thus, it prevents the conversion of angiotensin I to angiotensin II which exerts a vasopressor action on the arterial smooth muscles, leading to vasodilatation. Moreover, the studied drug can be used to reduce the risk of heart attacks and strokes [2].

A review of existing literature revealed that RAM is quantified in plasma by applying different analytical techniques like liquid chromatography coupled with tandem mass detection (TMD) [3-8], 
high performance liquid chromatography (HPLC) [9] and spectrophotometry [10]. LC-MS/MS has a significant advantage in selectivity and sensitivity. The high selectivity leads to advantageous separation pattern and sharper peak outline that are associated with improvement in method sensitivity and reduction in the time needed for analysis [11].

Previously published work on RAM have acceptable sensitivity and linearity ranges. The aim of this work was to introduce a liquid chromatographic method coupled with tandem mass detection (LC-TMD) with better sensitivity and wider linearity range than the previously published works. Moreover, the proposed method will be fully validated in line with US FDA guidelines, to introduce a simple and sensitive method with short analysis time for determination of RAM in human plasma during the pharmacokinetic studies.

\section{EXPERIMENTAL}

\section{Chemicals and reagents}

RAM was supplied by Sanofi Aventis Pharma, Egypt. Its purity was $100.4 \%$, as stated in the supplier documents. Atorvastatin was supplied by Aqa international Pharmaceuticals, India. Its purity was $99.9 \%$, as stated in the supplier documents. Human plasma samples were obtained from King Khaled hospital, Al-Kharj, KSA. Methanol, n-hexane, formic acid and propanol were products of Sigma Aldrich, while HPLC-grade water was purchased from Merck, Germany.

\section{Instrumentation}

The chromatographic analysis was performed on Waters Acquity ${ }^{\mathrm{TM}}$ liquid chromatograph. It was equipped with a tandem mass detector of triple quadrupole type.

\section{Chromatographic and mass conditions}

Chromatographic analysis was performed using Waters Acquity ${ }^{\mathrm{TM}}$ chromatograph with a column of RP-C 18 (15 cm x $2.1 \mathrm{~mm}, 1.7 \mu \mathrm{m}$ particle size). The mobile phase was water with $0.1 \%$ formic acid: methanol (1: 9, v/v). Degassing of the developing system was done for 15 min using a sonicator. The optimum flow rate used was 200 $\mu \mathrm{L}$ per minute.

The operation of the TMS tandem mass spectrometer was carried out at positive ionization mode which was applied for the analysis procedure at optimum instrumental working status.

\section{Standard solutions of RAM and IS}

The RAM and IS stock standard solutions (100 $\mu \mathrm{g} / \mathrm{mL}$ ) were separately prepared using methanol as solvent. All solutions were kept at $4-8{ }^{\circ} \mathrm{C}$. The working calibration solutions and controls were prepared through suitable dilutions using methanol as a diluting solvent. The IS working solution $(5 \mu \mathrm{g} / \mathrm{mL})$ was prepared via appropriate dilution of its stock standard solution using methanol as a diluting solvent. Working solutions for calibration were separately prepared at concentrations from 0.5 to $10,000 \mathrm{ng} / \mathrm{mL}$ via dilution of specific volumes of the stock standard solution using methanol as a diluting solvent.

\section{Preparation of quality control samples and calibration standards}

Appropriate portions of working standard solutions of RAM were used to spike $350 \mu \mathrm{L}$ blank plasma to prepare seven plasma standards from 0.05 - $1000 \mathrm{ng} / \mathrm{mL}$. Quality control (QC) samples having concentrations of $0.05 \mathrm{ng} / \mathrm{mL}$ (lower limit of quantification, LLOQ), $0.3 \mathrm{ng} / \mathrm{mL}$ (QCL), $400 \mathrm{ng} / \mathrm{mL}$ (QCM) and $800 \mathrm{ng} / \mathrm{mL}(\mathrm{QCH})$ were utilized during the validation procedure.

\section{Extraction procedure}

The extraction procedure was carried out by transferring $0.050 \mathrm{~mL}$ of IS working standard to the plasma sample spiked with RAM. The mixture was vortex-stirred for $20 \mathrm{sec}$. It was extracted by adding $0.005 \mathrm{~L}$ of $\mathrm{n}$-hexane: propanol (1:1 volume ratio). The resultant mixture was vortex-mixed for $60 \mathrm{sec}$, and then centrifuged for $4 \mathrm{~min}$ at $3000 \mathrm{rpm}$. Four millilitres of the organic layer was transferred to a centrifuge tube, followed by evaporation at $65^{\circ} \mathrm{C}$ using a vacuum concentrator. Reconstitution was done by adding $0.02 \mathrm{~mL}$ of the mobile phase. Finally, $0.010 \mathrm{~mL}$ of test material was subjected to chromatography.

\section{Validation protocol}

Validation of the analytical procedure is a very important step in method optimization and this task can be fulfilled according to the United States Food and Drug Administration (FDA) guidelines [12].

\section{Selectivity}

The probability of interference from endogenous substances in human plasma with the 
quantification procedure concerning RAM or IS was assessed by chromatographing blank plasma samples before any analyte analysis.

\section{Linearity}

Linearity was assessed by constructing calibration graphs utilizing seven test materials of RAM concentrations $0.05-1000 \mathrm{ng} / \mathrm{mL}$. Moreover, a blank plasma sample containing IS was chromatographed to ensure absence of any interference. The calibration graphs were plotted using the ratio between the RAM to IS peak area on different days.

\section{Lower limit of quantification (LLOQ)}

Analysis of seven replicates of plasma samples containing the LLOQ was done to determine the sensitivity of the proposed method.

\section{Accuracy and precision}

Inter-day precision and accuracy (P\&A) were assessed through the manipulation of five samples of each quality control concentration (in the linearity range) at different days. On the other hand, the intra-day P\&A were measured using five replicates of every quality control concentration within linearity range during the same $24 \mathrm{~h}$. Precision was assessed by calculating the $\% \mathrm{CV}$.

\section{Matrix effect and sample recovery}

RAM recovery was assessed by comparing the area of peak for three different concentrations within the linearity range in unextracted material spiked with the studied drug and subjected to all extraction steps [13].

The matrix effect was assessed by handling blank plasma samples from five sources with RAM using the QCM. The matrix effect was expressed by calculating the ratio between the area under the peak of the studied drug in extract to that of methanolic standards having equal concentrations. If the calculated ratio equals unity, this may indicate no matrix effect. On the other hand, if the ratio exceeds the value of unity, this may indicate ionization enhancement. On the other hand, a fraction value may suggest suppression of ionization.

Carryover with respect to RAM and the IS was tested using carryover test. The samples of the carryover test were analyzed in the following arrangement: plasma blank, ULOQ and finally, the plasma blank.

\section{Stability of RAM}

This was evaluated in four ways:

\section{Short-term stability}

All samples were left at room temperature for 4 $h$, which was very sufficient for the preparation of the sample. After $4 \mathrm{~h}$, a standard curve was plotted in one run using all stability samples, and stability samples were compared with fresh samples at the same concentrations.

\section{Post-preparative stability}

Three QC samples were prepared and left in the auto sampler at $25^{\circ} \mathrm{C}$ for $12 \mathrm{~h}$, which was the maximum expected storage time of the samples in auto sampler before injection. The samples were compared in the same manner as in shortterm stability test.

\section{Freeze-thaw stability}

This type of stability was evaluated by subjecting the plasma samples to 3 cycles of freeze-thaw at $-85^{\circ} \mathrm{C}$ during the day in 3 consecutive days. Analysis of the samples was done after the third cycle and calculation of their concentrations was carried out on the same day. Comparison of equal concentrations from the fresh and test samples were done to assess the analyte stability.

\section{Stability as a long-term issue}

Storage of three replicates of each quality control sample was done at $-85{ }^{\circ} \mathrm{C}$ for thirty days. Following the storage, stability was determined by comparing sample concentration to the mean concentration values obtained at first-day analysis. All calculations were based on a standard curve constructed within the same period. Then, the concentrations of stored samples were compared with those of fresh ones by calculating the percentage deviation.

\section{RESULTS}

\section{Optimized mass spectrometric conditions}

Positive ion mode scanning for the studied drug and IS was used to get full mass scan. The highest sensitivities in mass transitions were from $\mathrm{m} / \mathrm{z} 416.97 / 234.19$ and 559.39/440.27 for RAM and IS, respectively. Development of the method was carried out using the MRM mode to get the maximum selectivity and sensitivity for the proposed method. The working MRM parameters were optimized and given in Table 1. 
Table 1: Optimum instrumental parameters of the tandem mass spectrometer

\begin{tabular}{lcc}
\hline Parameter & Ramipril & IS \\
\hline Source temperature $\left({ }^{\circ} \mathrm{C}\right)$ & 120 & 120 \\
Dwell time per transition $(\mathrm{sec})$ & 0.063 & 0.146 \\
Capillary $(\mathrm{kV})$ & 3 & 3 \\
Desolvation temperature $\left({ }^{\circ} \mathrm{C}\right)$ & 400 & 400 \\
Desolvation gas flow $(\mathrm{L} / \mathrm{hr})$ & 800 & 800 \\
Cone $(\mathrm{V})$ & 30 & 35 \\
Collision energy $(\mathrm{V})$ & 30 & 20 \\
Mode of analysis & Positive & Positive \\
\hline
\end{tabular}

\section{Optimization of chromatography procedures}

It is desirable that samples are prepared in a simple and fast procedure that can be accomplished with small quantities of reagents, and should result in reproducible and acceptable drug recovery. There are several methods for sample preparation and drug extraction [14,15]. The method used in this work is the liquid-liquid extraction. Maximum recovery and optimum sample preparation time were attained using nhexane: propanol $(1: 1, v / v)$ as a solvent for extraction of the analyte from the plasma samples without the need to adjust $\mathrm{pH}$. The endogenous plasma matrix showed no interference, and IS did not change the analyte sensitivity and/or recovery. Chromatographic separation was accomplished using Waters $^{\mathrm{TM}}$ UPLC with a reversed phase $\mathrm{C}_{18}$ column, with $\mathrm{CH}_{3} \mathrm{OH}: 0.1 \% \mathrm{HCOOH}(4: 1)$ as mobile phase. The best sensitivity was attained using this mobile phase.

A brief analysis duration of 3 min was established on applying the optimized chromatographic conditions, where the average retention times were 1.7 and $2.0 \mathrm{~min}$ for RAM and IS, respectively.

\section{Performance of method and validation results}

\section{Selectivity}

The selectivity of the method can be attributed to the capability of the instrument to monitor drug fragments obtained from the parent analyte ion. Method selectivity was checked by chromatographing the human plasma extract samples which acted as blank experiment (Figure 1), and there was no significant interference coming from the endogenous materials in the human plasma free from the analyte.

\section{Quantification lower limit and linearity}

Excellent sensitivity was obtained by calculating the ratio between signal and noise. It was found to be 30 and 299 for the studied drug and IS, respectively. Based on the value of LLOQ, the analyte can be successfully quantified in plasma samples in concentrations as low as $0.05 \mathrm{ng} / \mathrm{mL}$, which reflects the high sensitivity of the proposed method.
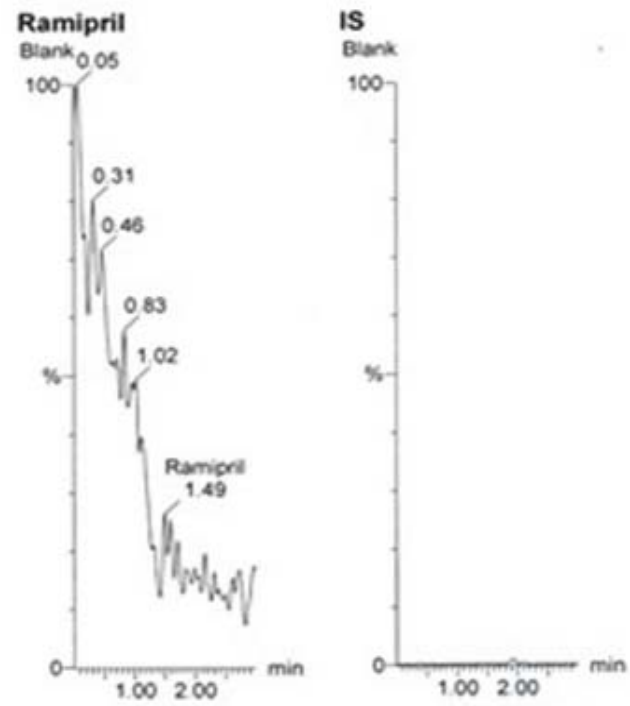

Figure 1: A chromatogram representing blank plasma samples

The standard curve was linear in the range of $0.05-1000 \mathrm{ng} / \mathrm{mL}$. Curve linearity was assessed by calculation of correlation coefficient $(r)$, and also by calculating the calibration standard concentrations.

The calibration equation was: $y=0.005$ ( \pm $0.00007) \mathrm{x}+0.0324( \pm 0.001)$, taking into consideration that $y$ is the peak area ratio of RAM to the IS, while $x$ is the concentration of RAM. During the validation process, the calibration curve was plotted and the average correlation coefficient was $0.9979 \pm 0.002$. The LLOQ was $0.05 \mathrm{ng} / \mathrm{mL}$, which was $105.00 \%$ accurate, with precision (CV\%) of 15.43. Figure 2 shows the LLOQ chromatograms.

\section{Assessment of precision and accuracy}

The inter-day and intra-day P\&A for the studied drug in quality control samples are presented in Table 2.

\section{Matrix effect and recovery}

A matrix effect ratio of 0.83 was obtained for QCM and so, minor suppression of ionization was implied, but it did not affect any of the validation parameters. 

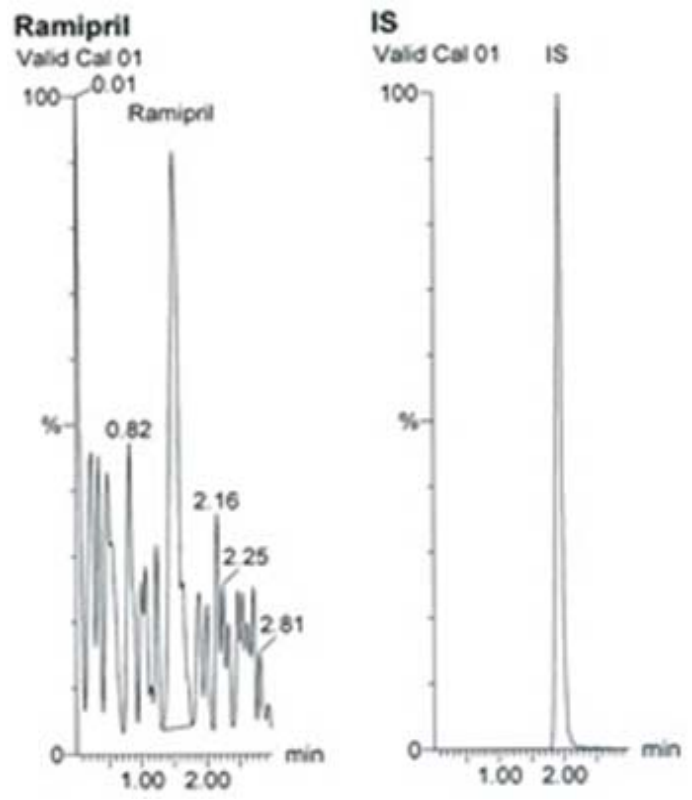

Figure 2: A chromatogram representing spiked plasma sample at LLOQ with the IS

Table 2: Precision and accuracy for RAM determination $(n=6)$

\begin{tabular}{lcc}
\hline \multirow{2}{*}{ Sample } & \multicolumn{2}{c}{$\begin{array}{c}\text { Recovery } \\
\text { (mean } \pm \text { RSD, \%) }\end{array}$} \\
\cline { 2 - 3 } & Intra-day & Inter-day $^{*}$ \\
\hline QCL & $104.24 \pm 13.62$ & $89.67 \pm 14.32$ \\
QCM & $97.63 \pm 7.10$ & $92.52 \pm 12.34$ \\
QCH & $98.75 \pm 4.53$ & $98.36 \pm 9.32$ \\
\hline *Mean recovery and relative standard deviation $(\mathrm{n}=6)$
\end{tabular}

RAM and IS recoveries were assessed as mentioned in the experimental part. The mean RAM recovery from spiked plasma samples was $88.74 \pm 2.97 \%$. The internal standard recovery was $87.22 \pm 0.97 \%$.

\section{Carryover}

Carryover was tested to be sure that there was no effect from neither RAM nor the IS on upcoming injections. Concerning this work, carryover was excluded completely.

\section{Stability assessment}

RAM stability was assured at RT for $4 \mathrm{~h}$ which was the peak sample preparation time. There was no observed degradation when the manipulated samples were stored for $12 \mathrm{~h}$. Variation in concentrations of quality control samples were absent, when compared to unstored samples following 3 cycles of freezing and thawing. Long term keeping ability of the studied drug was also studied at a temperature of $-85^{\circ} \mathrm{C}$ for thirty days (Table 3 ). Stock solution stability was examined at $8{ }^{\circ} \mathrm{C}$ for 7 days. The percentage recoveries were 99.14 and 97.84 for RAM and IS, respectively. This may indicate acceptable stability during a period of one week, which is the maximum storage period for the stock solutions.

Table 3: Assessment of drug stability

\begin{tabular}{lc}
\hline Item & $\begin{array}{c}\text { Change, relative to } \\
\text { unstored sample (\%) }\end{array}$ \\
\hline $4 \mathrm{~h}$ at $\mathrm{RT}$ & -0.95 \\
$Q C H$ & 1.45 \\
$Q C M$ & 7.94 \\
$Q C H$ & -3.56 \\
Post-preparation stability $\left(12 \mathrm{~h}\right.$ at $\left.25^{\circ} \mathrm{C}\right)$ \\
$Q C H$ & 4.72 \\
$Q C M$ & 7.65 \\
$Q C H$ & -4.96 \\
Long term stability $\left(-20^{\circ} \mathrm{C}\right.$ for 30 days) \\
$Q C H$ & 5.44 \\
$Q C M$ & -4.32 \\
$Q C H$ & \\
Freeze- thaw cycles (three cycles) & -3.31 \\
$Q C H$ & 3.92 \\
$Q C M$ & 1.43 \\
$Q C H$ &
\end{tabular}

\section{DISCUSSION}

In this work, the enormous sensitivity and selectivity of tandem mass spectrometric detection was coupled with liquid chromatography to establish a more sensitive analytical method with a wider linearity range. We preferred to use liquid-liquid extraction for sample preparation and analyte extraction from plasma to shorten the duration of analysis while enhancing recovery. After testing a variety of solvent systems, it was found that the optimum solvent extraction solvent was n-hexane: propanol $(1: 1, v / v)$. There was no need to adjust sample $\mathrm{pH}$ during analyte extraction process. This added to the simplicity of the method.

High sensitivity and optimum peak shape, as well as a brief analysis duration were attained via optimization. Atorvastatin was used as an internal standard since it was recovered successfully on using the cited extraction protocol. Moreover, it was eluted with a reasonable retention behavior on applying the optimized chromatographic conditions. Validation was performed with respect to how selective, accurate, linear and precise the method was. Carryover was tested to be sure that there were no residues from either RAM or IS affecting the next injections. RAM stability during the study was evaluated with respect to short term stability, post-preparation stability, freeze - thaw stability and long-term stability, which resulted in acceptable drug stability. 


\section{CONCLUSION}

A liquid chromatographic method coupled with TMSD has been successfully designed and applied for highly sensitive and selective determination of the widely prescribed antihypertensive drug, ramipril. Moreover, this method has the merits of reproducible sample recovery coupled with almost negligible matrix effect and simple preparation procedure for the sample. Thus, it is suitable for the monitoring of drug in plasma during pharmacokinetic investigations.

\section{DECLARATIONS}

\section{Acknowledgement}

This project was supported by the Deanship of Scientific Research at Prince Sattam bin Abdulaziz University under research group no. $2016 / 03 / 6600$. The authors gratefully acknowledge the Central Laboratories in College of Science, Prince Sattam Bin Abdul-Aziz University, Al Kharj, KSA for providing essential services to carry out this work.

\section{Conflict of interest}

No conflict of interest is associated with this work.

\section{Contribution of authors}

We declare that this work was done by the authors named in this article and all liabilities pertaining to claims relating to the content of this article will be borne by the authors.

\section{Open Access}

This is an Open Access article that uses a funding model which does not charge readers or their institutions for access and distributed under the terms of the Creative Commons Attribution License (http://creativecommons.org/licenses/by/ 4.0) and the Budapest Open Access Initiative (http://www.budapestopenaccessinitiative.org/rea d), which permit unrestricted use, distribution, and reproduction in any medium, provided the original work is properly credited.

\section{REFERENCES}

1. Lackland DT, Weber MA. Global burden of cardiovascular disease and stroke: hypertension at the core. Can J Cardiol2005; 31: 569-571.
2. Brunton LL, Lazo JS, Parker KL, eds. Renin and Angiotensin Goodman \& Gilman's The Pharmacological Basis of Therapeutics. New York: McGraw-Hill Medical Publishing Division; 2006. p. 173-211.

3. Gupta V, Jain R, Lukram O, Agarwal S, Dwivedi A. Simultaneous determination of ramipril, ramiprilat and telmisartan in human plasma using liquid chromatography tandem mass spectrometry. Talanta 2011; 83: 709-716.

4. Pilli NR, Inamadugu JK, Mullangi R, Karra VK, Vaidya $J R$, Seshagiri Rao J. Simultaneous determination of atorvastatin, amlodipine, ramipril and benazepril in human plasma by LC-MS/MS and its application to a human pharmacokinetic study. Biomed Chromatogr 2011; 25: 439-449.

5. Patel JR, Pethani TM, Vachhani AN, Sheth NR, Dudhrejiya AV. Development and validation of bioanalytical method for simultaneous estimation of ramipril and hydrochlorothiazide in human plasma using liquid chromatography-tandem mass spectrometry. J Chromatogr B 2014; 970: 53-59.

6. Elzanfaly ES, Abdel-Gawad SA. Simultaneous determination of ramipril, glimepiride and metformin in human plasma by ultra-performance liquid chromatography - tandem mass spectrometry. J Appl Pharm Sci 2017;7: 62 - 69.

7. Zhu Z, Vachareau A, Neirinck L. Liquid chromatographymass spectrometry method for determination of ramipril and its active metabolite ramiprilat in human plasma. $\mathrm{J}$ chromatogr B 2002; 779:297-306.

8. Pilli NR, Inamadugu JK, Mullangi $M$, Karra VK, Vaidya $J R$, Seshagiri Rao JV. Simultaneous determination of atorvastatin, amlodipine, ramipril and benazepril in human plasma by LC-MS/MS and its application to a human pharmacokinetic study. Biomed Chromatogr 2011; 25: 439-449.

9. Kurade V, Pai M, Gude R. RP-HPLC estimation of ramipril and telmisartan in tablets. Indian $\mathrm{J}$ Pharmaceut Sci 2009; 71: 148-152.

10. Al-Majed A, Belal F, Al-Warthan A. Spectrophotometric determination of ramipril (a novel ACE inhibitor) in dosage forms. Spectrosc Lett 2001; 34: 211-220.

11. Nakamura M. Analyses of benzodiazepines and their metabolites in various biological matrices by LC-MS (/MS). Biomed Chromatogr 2011; 25: 1283-1307.

12. Food Drug Administration (FDA). Guidance for Industry: Bioanalytical Method Validation US Department of Health and Human, Services Food and Drug Administration. and Center for Drug Evaluation and Research, 2001.

13. Matuszewski B, Constanzer M, Chavez-Eng C. Matrix effect in quantitative LC/MS/MS analyses of biological fluids: a method for determination of finasteride in human plasma at picogram per milliliter concentrations. Anal Chem 1998; 70: 882-889.

14. Zhu Z, Vachareau A, Neirinck L. Liquid chromatographymass spectrometry method for determination of ramipril 
and its active metabolite ramiprilat in human plasma. $J$ Chromatogr B 2002; 779: 297-306.

15. Tan A, Jin W, Deng F, Hussain S, Musuku A, Massé R. Bioanalytical method development and validation using incurred samples-Simultaneous quantitation of ramipril and ramiprilat in human EDTA plasma by LC-MS/MS. J Chromatogr B 2009; 877: 3673-3680. 